\title{
Kabasura Kudineer, a Siddha medicine against COVID-19 infection: scope and future perspective
}

\begin{abstract}
Indian Systems of Medicine (ISM) is defined as medicines which are considered to be of Indian origin or the medicine system which has adapted in to Indian culture. India has unmatched alternative system of medicine in the form of Ayurveda, Yoga and Naturopathy, Unani, Siddha, Homeopathy, which is now jointly referred to as AYUSH, recognized by the Government of India. Siddha medicine is one of the oldest and well documented medical systems of India. Retrospective studies revealed that Siddha medicines are used for prophylaxis and to treat viral diseases such as chicken pox, mumps, influenza, dengue etc. No specific drug is available till date to combat the rapid spread of COVID19. Further, exploring every possible treatment option will be of greater significance. Siddha medicine such as Kabasura Kudineer is recommended officially by the government for clinical management of viral infections. Data from on-going clinical trials of Kabasura Kudineer for improving the symptoms of COVID-19 are awaited with much interest. Kabasura Kudineer might be potent adjunct therapeutic option in the management of COVID-19.
\end{abstract}

Keywords: Indian Systems of Medicine, Siddha medicine, Kabasura Kudineer, COVID-19
Volume 14 Issue 3 - 202 I

\author{
Sugin Lal Jabaris S,Venkataraman $\mathrm{K}$ \\ Department of Pharmacology, Siddha Central Research Institute, \\ India \\ Correspondence: Sugin Lal Jabaris S, Department of \\ Pharmacology, Siddha Central Research Institute, Central \\ Council for Research in Siddha, Ministry of AYUSH, Govt. of \\ India, Anna Govt. Hospital Campus, Arumbakkam, Chennai-600 \\ 106, India, Email s.sugin@gov.in
}

Received: June 15, 202I | Published: June 30, 2021
Indian Systems of Medicine (ISM) is defined as medicines which are considered to be Indian origin or the medicine system which has adapted in to Indian culture. India has unmatched alternative system of medicine in the form of Ayurveda, Yoga and Naturopathy, Unani, Siddha, Homeopathy, which is now jointly referred to as AYUSH, recognized by the Government of India . In addition, ISM comprising of Ayurveda, Yoga, Unani and Siddha were practiced since time immemorial and much before the recognized health system came into vogue. ${ }^{1}$ Siddha medicine is one of the oldest (5000 years old) and well-documented medical systems of India and is practiced mainly in South India especially in Tamil Nadu, ${ }^{2}$ but also in Sri Lanka, Malaysia, Singapore and Mauritius on account of migration of people native to Tamil Nadu. The Government of India through its Ministry of AYUSH holds responsible for policy formulation, development and implementation of programs for the growth, development and propagation of Siddha System of Medicine.

In the current, pandemic situation, a myriad of strategies would be highly critical to combat the rapid virus spread and to treat the infection. The Ministry of AYUSH, Government of India has taken numerous initiatives and setup an interdisciplinary AYUSH research and has implemented various measures to control the spread of COVID-19 including a Task Force involving experts from diverse fields to formulate and develop strategies to control the spread of virus and infection. The Ministry of AYUSH, Govt. of India has issued an 'Advisory on Corona virus' to manage the outbreak which broadly comprises of preventive and prophylactic symptom management of COVID-19 like illnesses and also insights to interventions based on AYUSH systems of medicine through evidences for immunity boosting as well as help in improving the respiratory symptoms. Kabasura Kudineer (KK) is one of the drugs included in advisory of Govt. of India, released by the Ministry of AYUSH for symptomatic management of COVID-19. ${ }^{3,4} \mathrm{KK}$, is a classical Siddha formulation which comprises 15 herbal ingredients such as Zingiber officinale, Piper longum, Syzygium aromaticum, Tragia involucrata, Anacyclus pyrethrum, Andrographis paniculata, Hygrophilla auriculata,
Terminalia chebula, Justicia adhatoda, Plectranthus amboinicus, Costus speciosus, Tinospora cordifolia, Clerodendrum serratum, Sida acuta and Cypreus rotundus. ${ }^{5}$ It has been recommended to boil approximately $5 \mathrm{gms}$ of KK coarse powder in $240 \mathrm{ml}$ of water until it reduces to one-fourth of its quantity. Consumption of the concentrated 30 to $60 \mathrm{ml}$ of $\mathrm{KK}$ decoction twice or thrice daily can alleviate the symptoms of COVID-19. ${ }^{6}$ According to Siddha medicinal practice, 'Kaba' or 'Kabam' represents one of the three subtle physiological principles existing in our body (Vatham, Pitham, Kabam), which should be maintained in equilibrium for one's physical and mental well-being. Imbalance of 'Kabam' generally correlates with respiratory tract ailments. 'Sura' or 'Suram' means fever. 'Kudineer' represents a therapeutic recipe in the form of decoction.

The anti-viral properties of Siddha traditional formulations are backed with strong scientific evidences. ${ }^{7-9}$ In 2015, the KK formulation was used and found to be effective in swine flu influenza outbreaks..$^{10}$ The state government/research institutes have distributed Siddha medicines to millions in the Indian population with an intent to boost the immunity against COVID-19 with a special focus to the containment zones in Tamil Nadu, India. Short while ago, the Union Ministry of AYUSH has launched a massive nationwide campaign to distribute its proven poly herbal Siddha drug Kabasura Kudineer, aiming to strengthen its position in fight against COVID19 pandemic. In addition, state authorities have also opened exclusive Covid-19 treatment centre with Siddha System of Medicine in Tamil Nadu. It is also believed that traditional system of medicine improves general psychological quality of people thereby reducing infection risk. ${ }^{11}$

Recently, Kiran et al. provided in-silico methods to narrow down on nine phytoconstituents of KK such as Magnoflorine, 5-Hydroxy7,8-dimethoxyflavanone, Tinosponone, Cirsimaritin, Chrysoeriol, 6- Methoxygenkwanin, Vasicinone, Quercetin and Luteolin that may have high binding affinity and good binding interactions with SARSCoV-2 spike protein. Additionally the phyto-constituents were free from carcinogenic and tumorigenic properties. ${ }^{5}$ Further, Acetoside, 
Luteolin 7 -rutinoside, Rutin, Chebulagic acid, Syrigaresinol, Acanthoside, Violanthin, Andrographidine C, Myricetin, Gingerenone -A, Tinosporinone, Geraniol, Nootkatone, Asarianin, and Gamma sitosterol are the primary compounds from KK formulation which may inhibit COVID-19 by acting on the main protease (Mpro) with better energy. ${ }^{12}$ Moreover, many of the herbs which are present in the KK decoction had demonstrated anti-viral activity against dengue virus serotype 1 (DENV1), influenza A virus, and HIV, antiplatelet aggregation activity, immuno-modulatory and anti-inflammatory activities. $^{13}$ Recently, Shree Devi et al. provided in-vitro antiviral activity of water extract of KK was able to reduce viral RNA of $\mathrm{E}$ and $\mathrm{N}$ of novel Corona virus (SARS-CoV-2).${ }^{14}$ Further, these Siddha medicines might be enough potent to prevent and also be an adjunct treatment option against novel corona virus. Therefore, it is essential to elucidate the underlying molecular mechanisms of these medicines. In addition, patients with COVID-19 positive who were treated with integrated medicine -Zinc (150mg), Vitamin C (500mg) and Kabasura Kudineer (ZVcKK) benefited with shorter hospitalization and amelioration of symptoms. Furthermore, patients treated with ZVcKK had reduced the hospital stay by 7 days. During the conduct of the trial, there was no report of serious adverse events and mortality in the subjects. ${ }^{6}$ Currently, several clinical trials involving Siddha medicine either as stand-alone or adjunct with allopathic medicine that are taken up; such as a double blinded placebo controlled comparative clinical trial to evaluate the effectiveness of Siddha medicines, KabaSura Kudineer \& Nilavembu Kudineer along with standard allopathy treatment in the management of symptomatic COVID 19 patients (Clinical Trials Registry- India (CTRI) registry: CTRI/2020/ 08/027286). The efficacy of Siddha medicine, Kabasura Kudineer compared to Vitamin C \& Zinc (CZ) supplementation in the management of asymptomatic COVID-19 cases (CTRI/2020/05/025215). Also the efficacy and safety of Siddha treatment in COVID-19 patients (CTRI/2020/06/025625). The efficacy of Kabasura Kudineer and Vitamin C \& Zinc supplementation in asymptomatic COVID-19 patients is progressing which is a prospective, single centre, randomized open labelled clinical study (CTRI registry: CTRI/2020/05/025215) etc., are in various stages of completion/yet to be published. Further, more data continue to emerge, stressing on the beneficial effects of Siddha medicines through controlled clinical trials which might be potent to treat novel corona virus.

\section{Acknowledgments}

None.

\section{Conflicts of interest}

The author declares no conflicts of interest

\section{References}

1. Rudra S, Kalra A, Kumar A, et al. Utilization of alternative systems of medicine as health care services in India: Evidence on AYUSH care from NSS 2014. PLoS One. 12(2017) e0176916.

2. Thambyayah M, Amuthan A. Infantile seborrheic dermatitis: a pediatric Siddha medicine treatise. Clin Dermatol. 33(2015) 355-361.

3. Ministry of AYUSH, Advisory from Ministry of AYUSH for meeting the challenge arising out of spread of corona virus (covid-19) in India. New Delhi, India: Ministry of AYUSH, Government of India; 2020.

4. Jabaris SSL, Aanathalaskmi V. The current situation of COVID-19 in India. Brain Behav Immun. Health. 11(2021):100200.

5. Kiran G, Karthik L, Shree Devi MS, et al. In Silico computational screening of Kabasura Kudineer - Official Siddha Formulation and JACOM against SARS-CoV-2 spike protein. J Ayurveda Integr Med. 25 (2020)S0975-9476(20)30024-30023.

6. Jamuna D, Sathiyarajeswaran P, Shree Devi MS, et al. Survival analysis to assess the length of stay of novel coronavirus (COVID-19) patients under Integrated Medicine - Zinc, Vitamin C \&Kabasura Kudineer (ZVcKK). European Journal of Molecular \& Clinical Medicine. 2020;7(10) 13751387.

7. Jain J, Pai S, Sunil S. Standardization of in vitro assays to evaluate the activity of polyherbal siddha formulations against Chikungunya virus infection. Virus Dis. 2018;29(2018a):32-39.

8. Jain J, Narayanan V, Chaturvedi S, et al. In vivo evaluation of Withania somnifera-based Indian traditional formulation (Amukkara choornam), against chikungunya virus-induced morbidity and arthralgia. J Evid Based Integr Med. 2018;23:2156587218757661.

9. Jain J, Kumar A, Narayanan V, et al. Antiviral activity of ethanolic extract of Nilavembu Kudineera gainst dengue and chikungunya virus through in vitro evaluation. J Ayurveda Integr Med. 2020;11(3):329-335.

10. Thillaivanan S, Parthiban P, Kanakavalli K, et al. A review on Kabasura kudineer-a Siddha formulary prediction for swine flu. Int J Pharm Sci Drug Res. 2015;7(5):376-383.

11. Rajkumar RP. Ayurveda and COVID-19: Where psychoneuroimmunology and the meaning response meet. Brain Behav Immun. 2020;87:8-9.

12. Vincent S, Arokiyaraj S, Saravanan M, et al. Molecular Docking Studies on the Anti-viral Effects of Compounds From Kabasura Kudineer on SARS-CoV-2 3CLpro. Front Mol Biosci. 2020;7:613401.

13. Hossain MS, Urbi Z, Sule A, et al. Andrographis paniculata (Burm. f.) Wall. exNees: a review of ethnobotany, phytochemistry, and pharmacology. Sci World J. 2014;274905.

14. Shree Devi MS, Sathiyarajeswaran P Karthik L, Kanakavalli K Chandru $\mathrm{S}$, et al. In vitro Antiviral Activity of Kabasura Kudineer - Siddha Polyherbal Formulation Against Novel Coronavirus (SARS-CoV-2).

\section{Funding}

No funding sources. 